\title{
A Population Based Study Examining Language as a Predictor of Colorectal Cancer Screening Among Overweight and Obese Hispanic Adults in the United States
}

\author{
William S. Pearson ${ }^{*}, 1$, Shanta R. Dube ${ }^{2}$, Laura C. Seeff ${ }^{3}$, Earl S. Ford ${ }^{1}$, Ali H. Mokdad ${ }^{4}$ and \\ Michael F. Dulin ${ }^{5}$
}

\author{
${ }^{I}$ Behavioral Surveillance Branch, Division of Adult and Community Health, Centers for Disease Control and \\ Prevention, Atlanta, GA, USA \\ ${ }^{2}$ Epidemiology Branch, Office on Smoking and Health, Centers for Disease Control and Prevention, Atlanta, GA, USA \\ ${ }^{3}$ Office of Colorectal Cancer Programs, Division of Cancer Prevention and Control, Centers for Disease Control and \\ Prevention, Atlanta, GA, USA \\ ${ }^{4}$ Institute for Health Metrics and Evaluation, University of Washington, Seattle, WA, USA \\ ${ }^{5}$ Department of Family Medicine, Carolinas Medical Center, Charlotte, NC, USA
}

\begin{abstract}
Objective: Colorectal cancer (CRC) is one of the top two leading causes of cancer deaths in Hispanic/Latino adults living in the U.S., and CRC risk increases in people who are overweight. As the U.S. Hispanic population increases along with a growing prevalence of overweight and obesity, studies are needed to determine if overweight Hispanic adults suffer from disparities in their rates of CRC screening. Our study was able to examine the correlation between a preference for using the Spanish language and rates of screening for CRC using national survey data.

Design: 4,730 Hispanic participants, $\geq 50$ years, with a BMI $\geq 25 \mathrm{~kg} / \mathrm{m}^{2}$ from the 2006 Behavioral Risk Factor Surveillance System were stratified by survey language choice (English, $\mathrm{n}=3,499$; or Spanish, $\mathrm{n}=1,231$ ). Using adjusted logistic regression models, differences in receiving the recommended Fecal Occult Blood Test (F.O.B.T.) and/or either a colonoscopy or sigmoidoscopy were determined by language preference groups.

Results: Men who chose surveys in Spanish were significantly less likely to have received F.O.B.T. (0.29 O.R.; 0.13-0.64 95\% C.I.), sigmoidoscopy/colonoscopy (0.49 O.R.; 0.28-0.84 95\% C.I.) or either test (0.46 O.R.; 0.27-0.79 95\% C.I.) within the recommended time frames, compared to men choosing English. No significant differences were found among women.

Conclusions: Findings suggest that men with an elevated BMI who choose Spanish to complete a survey are less likely to receive the recommended CRC screening. Public health programs designed to improve access to CRC screening need to target this population in order to reduce the morbidity and mortality related to colorectal cancer.
\end{abstract}

\section{INTRODUCTION}

Recent census data indicate that the fastest growing ethnic group in the U.S. is Hispanic/Latino, with a total estimated population of approximately 43 million persons in 2005 [1]. Projections by the U.S. Census Bureau suggest that by the year 2050, the number of Hispanic persons in the U.S. will more than double [2]. The increasing Hispanic population within the United States is creating a demographic in which Spanish is the primary spoken language of many households. In fact, in 2006, the U.S. Census Bureau estimated that the number of persons aged 5 years and older who spoke predominantly Spanish and who reportedly spoke English "less than very well", was greater

*Address correspondence to this author at the Division of Adult and Community Health, Centers for Disease Control and Prevention, 4770 Buford Highway, NE MS K-66, Atlanta, GA 30326, USA; Tel: 770-4885429; E-mail: wpearson@cdc.gov than 16 million [3]. This demographic shift in the U.S. population has led to an increased body of research examining language preference among Hispanics in association with health outcomes. For example, Spanish language preference is associated with barriers to access and use of health care services $[4,5]$ and is associated with receiving less-efficient care $[6,7]$. These studies indicate that disparities in health care delivery exist because of a lack of language and cultural concordance between patients and their healthcare providers.

Language preference is an important measure of acculturation [8,9], and research has shown that limited English proficiency remains a significant barrier to access and use of health care services among Hispanic persons. Derose and Baker 2000 demonstrated that after adjusting for demographics, health status, and access to care variables, Latinos with fair and poor English proficiency reported significantly less visits to their healthcare provider than did 
English speaking non-Latinos [10]. A more recent study examining the impact of acculturation on the receipt of genetic cancer testing among a heterogeneous Hispanic population found that language preference was a significant predictor of awareness of the genetic cancer tests [11].

In 2003, the Centers for Disease Control and Prevention reported that colorectal cancer (CRC) was one of the top three diagnosed cancers and one of the top three leading causes of cancer attributed deaths among men and women in the United States [12]. In 2006, the American Cancer Society reported CRC as the second most common new cancer diagnosis among Hispanics, and CRC was the second leading cause of cancer related deaths for Hispanic men and the third leading cause of cancer related deaths for Hispanic women [13]. Furthermore, findings from Diaz and colleagues have demonstrated that Latinos choosing Spanish for response to a national survey were significantly less likely to have received recommended CRC screenings compared to non-Latinos and Latinos responding to the survey in English [14].

Since the mid-1990s, colorectal cancer screening (CRC) has been recommended to reduce the incidence, morbidity, and mortality of the disease [15-21]. Recent guidelines from the U.S. Preventive Services Task Force (USPSTF), The American Cancer Society, and the Multi-society task force $[22,23]$ state that colorectal cancer screenings should commence at 50 years of age for both men and women. For guidelines that recommend screening test intervals, F.O.B.T. is recommended annually, sigmoidoscopy every five years, or colonoscopy every ten years [24]. Despite these guidelines, recently reported rates of colorectal screening in the U.S. are not optimal, with approximately half of all people that were eligible not receiving appropriate testing [25].

Numerous studies have suggested that not only is obesity a risk factor for developing colorectal cancer [26-30] but being overweight or obese is also a growing problem among the U.S. Hispanic population [31-33]. Furthermore, research on predictors of screening has indicated that obesity and gender [34] as well as, Hispanic ethnicity [35] decrease the likelihood of receiving up-to-date screening. Therefore, investigation into the association of language barriers with receipt of CRC screening among overweight and obese Hispanic persons is warranted, and will provide the foundation for developing interventions aimed at improving screening rates in this sub-population. This study set out to determine if Spanish language preference decreased the likelihood of receiving CRC screening for overweight and obese Hispanic persons in the United States using data from a large national phone survey.

\section{METHODS}

Data were taken from the 2006 Behavioral Risk Factor Surveillance System (BRFSS) survey. The BRFSS is an ongoing, state-based, landline telephone survey that collects information on health risk behaviors, preventive health practices, and access to and use of health care services primarily related to chronic conditions among adults aged 18 years and older. The median cooperation rate, defined as the proportion of people interviewed of all eligible people who were actually contacted, was $74.5 \%$ and the median response rate was $51.4 \%$ [36].

Survey respondents were asked four questions to determine whether or not they had received CRC screening and the length of time since their last screening. The first question asked if they had received a kit to test at home, otherwise referred to as a fecal occult blood test (F.O.B.T.): "A blood stool test is a test that may use a special kit at home to determine whether the stool contains blood. Have you ever had this test using a home kit?" Those that responded "yes" were then asked about the amount of time since their last FOBT. These responses were categorized as within the past year $(<12$ months), within the past 2 years $(1$ year but $<$ 2 years ago), within the past 5 years $(2$ years but $<5$ years ago) and 5 or more years ago.

The third question determined the receipt of either a colonoscopy or a sigmoidoscopy and was phrased as "Sigmoidoscopy and colonoscopy are exams in which a tube is inserted into the rectum to view the bowel for signs of cancer or other health problems. Have you ever had either of these exams?" Those that responded "yes" were then asked the length of time since their last exam. Responses to length of time were categorized as within the past year $(<12$ months), within the past 2 years ( 1 year but $<2$ years ago), within the past five years ( 2 years but $<5$ years ago), within the past 10 years ( 5 years but $<10$ years ago) and 10 or more years ago.

Responses of "don't know/not sure" and "refused" were excluded from analyses. However, total percentages for excluded responses did not exceed $2 \%$ for length of time since last blood stool test and did not exceed $1 \%$ for other questions. These values were considered negligible and no bias was found between respondents choosing Spanish and English for non-response.

Survey respondents also reported their height and weight, which were used to calculate body mass index (BMI) in $\mathrm{kg} / \mathrm{m}^{2}$. Respondents were categorized as having normal weight (BMI $<25 \mathrm{~kg} / \mathrm{m}^{2}$ ), being overweight (BMI of 25 to $29.9 \mathrm{~kg} / \mathrm{m}^{2}$ ), or being obese (were classified as overweight. Those with a BMI $\geq 30 \mathrm{~kg} / \mathrm{m}^{2}$ ). The population used for this study was limited to those in the overweight and obese categories (BMI $\geq 25 \mathrm{~kg} / \mathrm{m}^{2}$ ).

A total of 4,730 Hispanic respondents were included for analysis. A Spanish translation of the BRFSS survey was completed for those states reporting that a significant proportion of residents did not speak English. A total of 26 states, (AZ, AR, CA, CO, CT, FL, ID, IL, IN, IA, KS, MA, NE, ME, NV, NJ, NM, NY, NC, OK, OR, RI, TX, UT, VA, WA, WY), had Spanish versions of the survey and were included in this study. Thus, language of survey (English or Spanish) was used as the main stratification variable.

Prevalence estimates were calculated for receipt of FOBT and sigmoidoscopy/colonoscopy independently and for receipt of either an FOBT within the past year or sigmoidoscopy/colonoscopy within the past 10 years or receipt of both tests. Prevalence was calculated for the total sample and separately for men and women. Differences based on language preference were examined using chisquare analyses and tested at an $\alpha=0.05$ level. 
To further test the association between language preference and receipt of $\mathrm{CRC}$, adjusted logistic regression models were used. The dependent variable was dichotomized into having the recommended screenings or not. The main predictor variable in these models was language preference for the survey (English or Spanish). We added the following covariates to our model based on their inclusion in previous studies examining the receipt of CRC screening. Models controlled for age, measured as a continuous variable; having health insurance coverage, (Yes/No); education, dichotomized into having graduated technical school or college and high school graduate or less; and whether or not a person had smoked at least 100 cigarettes in their life (Yes/No). All analyses were conducted using SUDAAN to control for the complex sampling design of the survey [37].

\section{RESULTS}

English-speaking survey respondents numbered 3,499 and Spanish-speaking survey respondents numbered 1,231. The average age of English-speaking respondents was 60.9, $+/-.3$ years. The average age of Spanish-speaking respondents was $60.4,+/-.6$ years. The proportion of female respondents was close to half for both language groups. Those choosing English had a greater educational attainment with one-fifth of respondents completing college or technical school compared to only six percent completing college or technical school among those choosing Spanish. Both language preference groups had relatively high levels of health insurance coverage with those choosing English at $86 \%$ and those choosing Spanish at $71 \%$. Finally, the percentage of respondents reporting ever having smoked 100 cigarettes in their lifetime was $47 \%$ for those choosing English and 40\% for those choosing Spanish (Table 1).

Table 1. Description of Sample Population: Hispanics 50 Years and Older with BMI $\geq 25 \mathrm{~kg} / \mathrm{m}^{2}$ by Survey Language Preference, U.S. 2006*

$\mathrm{N}=\mathbf{4 , 7 3 0}$

\begin{tabular}{|c|c|c|}
\hline \multirow{2}{*}{} & \multicolumn{2}{|c|}{ Survey Language Preference } \\
\cline { 2 - 3 } & English $(\mathbf{n}=\mathbf{3 , 4 9 9 )}$ & Spanish $(\mathbf{n}=\mathbf{1 , 2 3 1})$ \\
\hline \hline Average age in years $\dagger$ & $60.9,+/-.3$ & $60.4,+/-.6$ \\
\hline$\%$ Female $\ddagger$ & $50.6 \%,(1.9 \%)$ & $48.5 \%,(3.2 \%)$ \\
\hline $\begin{array}{c}\% \text { Completing college } \\
\text { or technical school }\end{array}$ & $21.3 \%,(1.6 \%)$ & $6.2 \%,(1.3 \%)$ \\
\hline $\begin{array}{c}\% \text { Having health } \\
\text { insurance } \ddagger\end{array}$ & $85.6 \%,(1.4 \%)$ & $70.9 \%,(2.9 \%)$ \\
\hline $\begin{array}{c}\% \text { Having smoked } 100 \\
\text { cigarettes in lifetime } \ddagger\end{array}$ & $47.3 \%,(1.8 \%)$ & $39.5 \%,(3.2 \%)$ \\
\hline
\end{tabular}

Source: 2006 Behavioral Risk Factor Surveillance System (BRFSS).

* All estimates are weighted.

$\dagger$ Mean and standard error of the mean.

$\ddagger$ Estimate and standard error of the estimate.

Chi-square analyses demonstrated that significant differences in the receipt of the recommended screenings existed between Spanish-speaking survey respondents and English-speaking survey respondents. Spanish-speaking respondents were significantly less likely to have received the recommended screenings. When looking at both males and females together for receiving FOBT, Spanish-speaking respondents had a significantly smaller proportion receiving the test $(\mathrm{p}<.01)$. When looking at sigmoidoscopy/colonoscopy specifically, differences in screening rates between the two language preference groups were significant for males and females together and the two sexes independently, demonstrating that English-speaking survey respondents had greater proportions indicating that they had received the recommended testing $(p<.01)$. When examining differences for the receipt of either test, significant differences were found for males and females together $(p<.01)$ as well as males $(\mathrm{p}<.01)$ and females $(\mathrm{p}=.04)$ independently (Table 2$)$.

Table 2. Estimates for the Receipt of Colorectal Cancer Screening* by Hispanics 50 Years and Older with BMI $\geq 25 \mathrm{~kg} / \mathrm{m}^{2}$ Based on Survey Language Preference, U.S. 2006 (Chi-Square Tests)*

$\mathbf{N}=\mathbf{4 , 7 3 0}$

FOBT**

\begin{tabular}{|c|c|c|c|}
\hline \multirow{2}{*}{} & \multicolumn{3}{|c|}{ Survey Language Preference } \\
\cline { 2 - 4 } & English & Spanish & p \\
\hline \hline All & $13.11 \%,(1.25)$ & $7.17 \%,(1.52)$ & $<.01$ \\
\hline Males & $15.50 \%,(2.08)$ & $4.33 \%,(1.49)$ & $<.01$ \\
\hline Females & $10.81 \%,(1.39)$ & $10.20 \%,(2.63)$ & .84 \\
\hline
\end{tabular}

Sigmoid/Colon $\dagger$

\begin{tabular}{|c|c|c|c|}
\hline \multirow{2}{*}{} & \multicolumn{3}{|c|}{ Survey Language Preference } \\
\cline { 2 - 4 } & English & Spanish & p \\
\hline \hline All & $53.42 \%,(1.92)$ & $30.69 \%,(2.76)$ & $<.01$ \\
\hline Males & $44.21 \%,(2.96)$ & $24.95 \%,(4.07)$ & $<.01$ \\
\hline Females & $48.88 \%,(2.47)$ & $36.75 \%,(3.59)$ & $<.01$ \\
\hline
\end{tabular}

Eitherł

\begin{tabular}{|c|c|c|c|}
\hline \multirow{2}{*}{} & \multicolumn{3}{|c|}{ Survey Language Preference } \\
\cline { 2 - 4 } & English & Spanish & p \\
\hline \hline All & $51.40 \%,(1.93)$ & $35.27 \%,(2.95)$ & $<.01$ \\
\hline Males & $50.31 \%,(2.98)$ & $27.94 \%,(4.23)$ & $<.01$ \\
\hline Females & $52.45 \%,(2.46)$ & $43.08 \%,(3.86)$ & .04 \\
\hline
\end{tabular}

Source: 2006 Behavioral Risk Factor Surveillance System (BRFSS).

* Estimates and standard errors of the estimate.

** Fecal Occult Blood Test within the past 12 months.

$\dagger$ Sigmoidoscopy or colonoscopy within the past 10 years.

\$ Having either Fecal Occult Blood Test within the past 12 months or sigmoidoscopy or colonoscopy within the past 10 years.

Adjusted models demonstrated that in the combined male and female sample, Spanish-speaking respondents were significantly less likely to have received FOBT (0.58 O.R., 0.36-0.95 C.I.), sigmoidoscopy/colonoscopy (0.58 O.R., 0.42-0.81 C.I.) or either of the two tests (0.61 O.R., 0.440.85 C.I.). These results held true when limiting the analyses 
to a sample of males only. Males choosing Spanish language were significantly less likely to have received FOBT $(0.29$, 0.13-0.64 C.I.), sigmoidoscopy/colonoscopy (0.49 O.R., $0.28-0.84)$ or either of the two tests (0.46 O.R., 0.27-0.79). However, when looking specifically at females, no significant differences were found between the two language preference groups for any of the screening tests (Table $\mathbf{3}$ ).

Table 3. Adjusted Logistic Regressions for the Likelihood of Receiving Colorectal Cancer Screening by Hispanics 50 Years and Older with BMI $\geq 25 \mathrm{~kg} / \mathrm{m}^{2}$, U.S., 2006*

\begin{tabular}{|c|c|c|c|c|c|c|}
\hline \multirow{2}{*}{$\mathrm{N}=4,730$} & \multicolumn{2}{|c|}{ FOBT ** } & \multicolumn{2}{|c|}{ Sigmoid/Colon $\dagger$} & \multicolumn{2}{|c|}{ Eitherł } \\
\hline & O.R. & 95\% C.I. & O.R. & 95\% C.I. & O.R. & $95 \%$ C.I. \\
\hline \multicolumn{7}{|l|}{ All } \\
\hline Spanish & 0.58 & $0.36-0.95$ & 0.58 & $0.42-0.81$ & 0.61 & $0.44-0.85$ \\
\hline English & 1.00 & $1.00-1.00$ & 1.00 & $1.00-1.00$ & 1.00 & $1.00-1.00$ \\
\hline \multicolumn{7}{|l|}{ Males } \\
\hline Spanish & 0.29 & $0.13-0.64$ & 0.49 & $0.28-0.84$ & 0.46 & $0.27-0.79$ \\
\hline English & 1.00 & $1.00-1.00$ & 1.00 & $1.00-1.00$ & 1.00 & $1.00-1.00$ \\
\hline \multicolumn{7}{|l|}{ Females } \\
\hline Spanish & 1.03 & $0.57-1.85$ & 0.70 & $0.48-1.03$ & 0.80 & $0.55-1.15$ \\
\hline English & 1.00 & $1.00-1.00$ & 1.00 & $1.00-1.00$ & 1.00 & $1.00-1.00$ \\
\hline
\end{tabular}

Source: 2006 Behavioral Risk Factor Surveillance System (BRFSS)

* Controlling for age, health insurance coverage, education and ever having smoked 100 cigarettes in lifetime.

** Fecal Occult Blood Test within the past 12 months.

$\dagger$ Sigmoidoscopy or colonoscopy within the past 10 years.

$\ddagger$ Having either Fecal Occult Blood Test within the past 12 months or sigmoidoscopy or colonoscopy within the past 10 years.

\section{DISCUSSION}

This study has used recent aggregate, state-based data to demonstrate that barriers to receiving recommended colorectal cancer screenings exist for overweight and obese Hispanic persons in the U.S. The findings from this large study suggest that Spanish language preference is a significant predictor of not receiving recommended colorectal cancer screening among Hispanic males who are overweight or obese. Significant differences were not observed among women.

In our study, we found that language preference was associated with reduced likelihood of CRC screening among men, but not among women. It should be noted that other studies have found that women were less likely to have received CRC screening as compared to men. Work conducted by Heo and colleagues found that women in obesity classes I and II (BMI 30-40 kg/ ${ }^{2}$ ) were less likely to have received sigmoidoscopies as compared to their obese male counterparts [38]. Rosen and Schneider found significantly lower rates of CRC screening among morbidly obese women compared to morbidly obese men [39]. Another study conducted by Peterson and colleagues found that among a nationally representative sample of adults, women were somewhat less likely than men to have received a lower endoscopy screening than men, irrespective of BMI [40].
The findings from these studies suggest that differences observed by gender could possibly be attributed to issues of embarrassment. For example, in the studies conducted by Heo et al. and Rosen et al. [38, 39], the authors suggest that embarrassment related to obesity may have prevented women from seeking care. In the study conducted by Peterson et al. [40], it was suggested that because of the nature of the sigmoidoscopy procedure, women may have been less likely to receive such a screening due to negative expectations, including embarrassment or pain. Our study expands on these previous reports in that it focuses on Hispanic persons with elevated BMI and the potential association of language preference to receiving $\mathrm{CRC}$ screenings. We found that among Hispanic men, those preferring to complete the survey in Spanish were less likely to receive CRC screening. This association may be due to the fact that men are less likely to make visits to their physicians for regular care [41]. This coupled with a language barrier will possibly make men even less likely to receive physician recommended screenings such as CRC screening as observed in the present study. For women, language preference may be less of a barrier than the aforementioned factors of negative expectations such as embarrassment and pain. Our non-significant findings among Hispanic, overweight and obese women merit further investigation.

The findings from this study related to language are similar to those of Diaz and colleagues who used the same data to demonstrate that among a US sample of Latinos, language was a barrier for receiving recommended CRC screenings [14]. We have built upon this important study by focusing our analyses on the same population, but with an added risk factor; those with elevated BMI.

Other smaller studies in this area also suggest that language barriers play a significant role in decreasing CRC screening rates among Hispanics and others with lower English literacy skills. Fernandez and colleagues [42] examined CRC screening among Latinos along the U.S.Mexico border in Texas. These researchers found that among numerous other barriers to care, such as system level barriers including lack of insurance and cost of care, interpersonal level barriers such as language differences between the patient and the provider were also noted as a principal barrier. For instance, several study participants in this focus group noted that they routinely traveled to Mexico for care because they preferred to speak to their physicians in Spanish rather than English. Our study found that while controlling for two previously mentioned barriers such as health insurance coverage and education as a proxy for socio-economic status, language still was observed as a significant factor in predicting screening.

Other studies have discovered similar situations where those with lower English literacy skills had difficulty in understanding the complex vocabulary used in CRC recommendations [43]. As the population of Hispanic persons with lower English literacy skills increases, screening rates among this group of persons potentially will remain low and could result in an increased incidence of undetected polyps or cancers. Therefore, our study points out an opportunity for a public health intervention to increase screening rates for this population. Furthermore, the BRFSS 
can be a useful mechanism for monitoring the effectiveness of these interventions to target this and other vulnerable populations.

Another factor that will affect the rates of colorectal cancer in the future is the aging of the U.S. population. Estimates for the number of persons with colorectal cancer are predicted to increase over fifty percent by the year 2020 due to the aging of the population [44]. Furthermore, recent work conducted by Yabroff and colleagues [45] project that by the year 2020, cost of care for colorectal cancer will range anywhere from $\$ 2.6$ billion to $\$ 5.3$ billion annually among those 65 years of age and older, depending on the stage of the cancer. A growing elderly population coupled with low levels of screening for a costly disease among an expanding ethnic demographic in our nation will place an increased burden on our already-strained healthcare system.

As mentioned previously, obesity has been suggested as a risk factor for developing colorectal cancer [26-30] and obesity has been noted as an increasing problem among Hispanic populations [31-33]. As obesity continues to be a problem in the U.S., it will contribute to greater numbers of persons being at risk for developing colorectal cancer and could likely increase the incidence of this cancer. Therefore, it is imperative to understand barriers to receiving timely colorectal cancer screening, and designing interventions aimed at overcoming these barriers.

Several methods for addressing the problem of language barriers have been researched. One method is the implementation of interpreter services within healthcare facilities. Two recent systematic literature reviews, one conducted by Karliner and colleagues [46] and a second conducted by Flores [47] found numerous peer-reviewed articles studying the impact of professional interpreter services on clinical care outcomes. Both of these reviews reported positive outcomes such as better patient-physician communication, higher utilization of health services, improved clinical outcomes and increased patient satisfaction where interpreter services were used.

A second potentially effective intervention is to ameliorate lack of patient provider language concordance by training medical personnel to speak Spanish. Some American medical schools have adopted educational programs to train their students to be able to better serve Latino communities. Examples include the Program in Medical Education for the Latino Community (PRIME-LC) at the University of California-Irvine (UCI) School of Medicine [48] and a collaborative effort among Brown University, Brown Medical School and the Rhode Island Hospital [49].

A third method for addressing this problem is the public health approach of providing culturally sensitive and linguistically appropriate health promotion materials to at risk populations. Examples here include the Centers for Disease Control and Prevention's Screen for Life: National Colorectal Cancer Action Campaign [50] and a booklet published by the National Cancer Institute entitled "Facing Forward: Life after Cancer Treatment" [51].

These three different methods (providing translators, teaching Spanish to health providers, and developing Spanish language materials) would be useful in addressing the findings from this study. And results from future iterations of the BRFSS can be analyzed geographically to determine the effectiveness of these interventions in individual communities, or aggregated to look for reductions in disparities for the targeted populations across the U.S. as a whole.

Several limitations should be considered when interpreting these analyses. First, the BRFSS is a land-line telephone survey, which excludes persons with no telephone or those with a cell phone only. A report from the U.S. Census Bureau indicated that Hispanic households have a slightly lower rate of land-line telephone coverage than do white households [52]. Because of this lower rate of coverage, there is a possibility that some Hispanic households would not have had the opportunity to participate in this survey. However, because of the large sample size of the BRFSS, a relatively large sample of Hispanic persons was obtained, thereby providing a representative sample and taking into account geographic variation.

A second limitation is that this survey calculated BMI from a self report of height and weight. This introduces the possibility of self-report bias that likely results in underreporting of persons with BMI $\geq 25 \mathrm{~kg} / \mathrm{m}^{2}$. Consequently, our study may underestimate the number of persons at risk for developing colorectal cancer. However, reliability studies of the BRFSS questionnaires in various settings have reported $\mathrm{K}$ coefficients of 0.77 to 0.96 for BMI and categories of overweight or obese [53-55] and correlation coefficients of 0.84 to 0.94 for height, weight and BMI [56]. Future studies of self-reported height and weight are planned for further validation of these measures in the BRFSS.

A third limitation is the determination of both sigmoidoscopy and colonoscopy procedures. It is not possible to determine if either of the procedures were routine screenings or if they were diagnostic procedures. Furthermore, the linking of the two procedures in one question does not allow for precise measurement of their respective numbers received by the survey respondents.

A fourth limitation is that it was not possible to determine specifically why a person did not receive the screening. The BRFSS neither asked if the screening was recommended by a physician, nor did the survey follow-up with questions as to why the person did not receive the screening. The findings from this study only point to an association between limited English proficiency and lack of screening for overweight and obese Hispanic men.

\section{CONCLUSIONS}

Despite these limitations, this study suggests that Spanish language preference is related to a lower likelihood of receiving colorectal cancer screening among overweight and obese Hispanic males in the U.S. and alerts the public health community to a potential problem that can significantly impact our healthcare system in the near future. Given the growing Hispanic population and the increasing problem of obesity of persons in the U.S., this finding identifies a population that may need increased outreach. Therefore, it is imperative for the public health and medical community to implement effective methods of reaching this at risk population so as to increase screening rates and decrease the 
morbidity and mortality of the disease. By reducing disparities in colorectal screening for this vulnerable population, we can improve health outcomes not only for the Hispanic community, but also for our nation as a whole.

\section{ACKNOWLEDGEMENTS}

An abstract of this paper was presented at the $36^{\text {th }}$ annual North American Primary Care Research Group (NAPCRG) meeting in Rio Grande, Puerto Rico, November 15-19, 2008.

Disclaimer: The findings and conclusions in this report are those of the authors and do not necessarily represent the views of the Centers for Disease Control and Prevention.

\section{REFERENCES}

[1] U.S. Census Bureau. Race and Hispanic or Latino origin of the population for the United States: 2004 and 2005. [Accessed May 7 2007]. Available at: http://www.census.gov/Press-Release/www/ 2006/nationalracetable1.pdf

[2] U.S. Census Bureau. Projections of the resident population by race, Hispanic origin and nativity: 2025 and 2050. Hyattsville, MD: US Census Bureau; 2003.

[3] U.S. Census Bureau. American fact finder, language spoken at home, 2006 American Community Survey. [Accessed May 7 2007]. Available at: http://www.factfinder.census.gov

[4] Pearson WS, Ahluwalia IA, Ford ES, Mokdad AH. Language preference as a predictor of access to and use of health care services among Hispanics in the U.S. Ethn Dis 2008; 18: 93-7.

[5] Garbers S, Chiasson MA. Inadequate functional health literacy in Spanish as a barrier to cervical cancer screening among immigrant Latinas in New York City. Prev Chronic Dis 2004; 1: A07.

[6] Hampers LC, Cha S, Gutglass DJ, Binns HJ, Krug SE. Language barriers and resource utilization in a pediatric emergency department. Pediatrics 1999; 103: 1253-6.

[7] Goldman RD, Amin P, Macpherson A. Language and length of stay in the pediatric emergency department. Pediatr Emerg Care 2006; $22:$ : 640-3.

[8] Lara M, Gamboa C, Kahramanian MI, Morales LS, Bautista DE. Acculturation and Latino health in the United States: a review of the literature and its sociopolitical context. Annu Rev Public Health 2005; 26: 367-97.

[9] Abraido-Lanza AF, Armbrister AN, Florez KR, Aguirre AN. Toward a theory-driven model of acculturation in public health research. Am J Public Health 2006; 96: 1342-6.

[10] Derose KP, Baker DW. Limited english proficiency and Latinos' use of physician services. Med Care Res Rev 2000; 57: 76-91.

[11] Vadaparampil ST, Wideroff L, Breen N, Trapido E. The impact of acculturation on awareness of genetic testing for increased cancer risk among Hispanics in the year 2000 National Health Interview Survey. Cancer Epidemiol Biomarkers Prev 2006; 15: 618-23.

[12] U.S. Cancer Statistics Working Group. United States Cancer Statistics: 2003 Incidence and Mortality. Atlanta: U.S. Department of Health and Human Services, Centers for Disease Control and Prevention and National Cancer Institute 2006.

[13] American Cancer Society. American Cancer Society Guidelines for the Early Detection of Cancer. Atlanta US; 2006. Available at: http://www.cancer.org/docroot/PED/content/PED_2_3X_ACS_Can cer Detection Guidelines 36.asp

[14] Diaz JA, Roberts MB, Goldman RE, Weitzen S, Eaton CB. Effect of Language on colorectal cancer among latinos and non-latinos. Cancer Epidemiol Biomarkers Prev 2008; 17: 2169-73.

[15] Newcomb PA, Norfleet RG, Storer BE, Surawicz TS, Marcus PM. Screening sigmoidoscopy and colorectal cancer mortality. J Natl Cancer Inst 1992; 84: 1572-5.

[16] Selby JV, Friedman GD, Quesenberry CP, Weiss NS. A casecontrol study of screening sigmoidoscopy and mortality from colorectal cancer. N Engl J Med 1992; 326: 653-7.

[17] Mandel JS, Bond JH, Church TR, et al. Reducing mortality from colorectal cancer by screening for fecal occult blood. N Engl J Med 1993; 328: 1365-71.

[18] Müller AD, Sonnenberg A. Protection by endoscopy against death from colorectal cancer: a case-control study among veterans. Arch Intern Med 1995; 155: 1741-8.
[19] Hardcastle JD, O'Chamberlain JO, Robinson MHE, et al. Randomised controlled trial of faecal-occult-blood screening for colorectal cancer. Lancet 1996; 348: 1472-7.

[20] Kronborg O, Fenger C, Olsen J, Jorgensen OD, Sondergaard O. Randomised study of screening for colorectal cancer with faecaloccult-blood test. Lancet 1996; 348: 1467-71.

[21] Mandel JS, Church TR, Bond JH, et al. The effect of fecal occultblood screening on the incidence of colorectal cancer. N Engl J Med 2000; 343: 1603-7.

[22] United States Preventive Services Task Force (USPSTF) Guide to Clinical Preventive Services, 2006. [Accessed Sept 17 2007]. Available from: http://www.ahrq.gov/clinic/pocketgd/pocketgd. htm

[23] Smith RA, Cokkinides V, Eyre HJ. American Cancer Society guidelines for the early detection of cancer, 2004. CA Cancer J Clin 2004; 54: 41-52.

[24] Winawer S, Fletcher R, Rex D, et al. Colorectal cancer screening and surveillance: clinical guidelines and rationale: Update based on new evidence. Gastroenterology 2003; 124: 544-60.

[25] Shapiro JA, Seeff LC, Thompson TD, et al. Colorectal cancer test use from the 2005 National Health Interview Survey. Cancer Epidemiol Biomarkers Prev 2008; 17: 1623-30.

[26] Murphy TK, Calle EE, Rodriguez C, Kahn HS, Thun MJ. Body mass index and colon cancer mortality in a large prospective study. Am J Epidemiol 2000; 152: 847-54.

[27] Moore LL, Bradlee ML, Singer MR, et al. BMI and waist circumference as predictors of lifetime colon cancer risk in Framingham Study adults. Int J Obes 2004; 28: 559-67.

[28] Batty GD, Shipley MJ, Jarrett RJ, Breeze E, Marmot MG, Smith GD. Obesity and overweight in relation to organ-specific cancer mortality in London (UK); findings from the original Whitehall study. Int J Obes 2005; 29: 1267-74

[29] Pischon T, Lahmann PH, Boeing H, et al. Body size and risk of colon and rectal cancer in the European Prospective Investigation into Caner and Nutrition (EPIC). J Natl Cancer Inst 2006; 98: 92031.

[30] Adams KF, Leitzmann MF, Albanes D, et al. Body Mass and Colorectal Cancer Risk in the NIH-AARP Cohort. Am J Epidemiol 2007; 166: 36-45.

[31] Forrest KY, Leeds MJ. Prevalence and associated factors of overweight among Mexican-American adolescents. J Am Diet Assoc 2007; 107: 1797-800.

[32] Okosun IS, Boltri JM, Eriksen MP, Hepburn VA. Trends in abdominal obesity in young people: United States 1988-2002. Ethn Dis 2006; 16: 338-44.

[33] Flegal KM, Ogden CL, Carroll MD. Prevalence and trends in overweight in Mexican-American adults and children. Nutr Rev 2004; 62: S144-8.

[34] Rosen AB, Schneider EC. Colorectal cancer screening disparities related to obesity and gender. J Gen Intern Med 2004; 19: 332-8.

[35] Shokar NK, Carlson CA, Weller SC. Prevalence of colorectal cacner testing and screening in a multiethnic primary care population. J Commun Health 2007; 32: 311-23.

[36] Centers for Disease Control and Prevention. Behavioral Risk Factor Surveillance System (BRFSS): Turning information into health. [Accessed May 1 2007] Available at: http://www.cdc. gov/brfss

[37] RTI International. (SUDAAN) ${ }^{9}$. [Accessed Mar 7 2007]. Available at: http://www.rti.org/sudaan

[38] Heo M, Allison DB, Fontaine KR. Overweight, obesity, and colorectal cancer screening: disparity between men and women. BMC Public Health 2004; 4: 53

[39] Rosen AB, Schneider EC. Colorectal cancer screening disparities related to obesity and gender. J Gen Intern Med 2004; 19: 332-8.

[40] Peterson NB, Murff HJ, Ness RM, Dittus RS. Colorectal cancer screening among men and women in the United States. J Womens Health 2007; 16: 57-65.

[41] Aday LA. Indicators and predictors of health services utilization. In: Williams SJ, Torrens PR, Eds. Introduction to Health Services. New York: Delmar 1993; pp. 58-60.

[42] Fernandez ME, Wippold R, Torres I, et al. Colorectal-cancer screening among Latinos from U.S. cities along the Texas-Mexico border. Cancer Causes Control 2007; Epub ahead of print.

[43] Davis TC, Dolan NC, Ferreira MR, et al. The role of inadequate health literacy skills in colorectal cancer screening. Cancer Invest 2001; 19: 193-200. 
[44] Mariotto AB, Yabroff KR, Feuer EJ, De Angelis, Brown M. Projecting the number of patients with colorectal carcinoma by phases of care in the US: 2000-2020. Cancer Causes Control 2006; 17: $1215-26$.

[45] Yabroff KR, Mariotto AB, Feuer E, Brown ML. Projections of the costs associated with colorectal cancer care in the United States, 2000-2020. Health Econ 2007. Epub. Ahead of Print

[46] Karliner LS, Jacobs EA, Chen AH, Mutha S. Do professional interpreters improve clinical care for patients with limited English proficiency? A systematic review of the literature. Health Serv Res 2007; 42: 727-54.

[47] Flores G. The impact of medical interpreter services on the quality of health care: a systematic review. Med Care Res Rev 2005; 62: 255-99.

[48] Manetta A, Stephens F, Rea J, Vega C. Addressing health care needs of the Latino community: one medical schools approach. Acad Med 2007; 82: 1145-51.

[49] Monroe AD, Shirazian T. Challenging linguistic barriers to health care: Students as medical interpreters. Acad Med 2004; 79: 118-22.

[50] Cooper CP, Gelb CA, Jameson H, Macario E, Jorgensen CM, Seeff L. Developing English and Spanish television public service announcements to promote colorectal cancer screening. Health Promot Pract 2005; 6: 385-93.

[51] National Cancer Institute. Facing Forward: Life after Cancer treatment. [Accessed October 23 2007] Available at: http://www. cancer.gov/espanol/cancer/siga-adelante

[52] U.S. Census Bureau. Extended measures of well-being: living conditions in the United States, 2003. [Accessed Apr 11 2007]. Available at: http://www.census.gov/prod/2007pubs/p70-110.pdf

[53] Stein AD, Courval JM, Lederman RI, Shea S. Reproducibility of responses to telephone interview: demographic predictors of discordance in risk factor status. Am J Epidemiol 1995 141: 1097105 .

[54] Brownson RC, Jackson-Thomspon J, Wilkerson JC, Kiani F. Reliability of information on chronic disease risk factors collected in the Missouri Behaviroal Risk Factor Surveillance System questionnaire. Epidemiology 1994; 5: 545-9.

[55] Stein AD, Lederman RI, Shea S. Reproducibility of the women's module of the Behavioral Risk Factor Surveillance System questionnaire. Ann Epidemiol 1996; 647-52.

[56] Shea S, Stein AD, Lantigua R, Basch CE. Reliability of the Behavioral Risk Factor Survey in a triethnic population. Am J Epidemiol 1991; 133489-500.

Received: March 4, 2009

Revised: April 9, 2009

Accepted: April 15, 2009

(C) Pearson et al.; Licensee Bentham Open.

This is an open access article licensed under the terms of the Creative Commons Attribution Non-Commercial License (http://creativecommons.org/licenses/by$\mathrm{nc} / 3.0 /$ ) which permits unrestricted, non-commercial use, distribution and reproduction in any medium, provided the work is properly cited. 